\title{
Cerebral Subcortex
}

National Cancer Institute

\section{Source}

National Cancer Institute. Cerebral Subcortex. NCI Thesaurus. Code C98712.

The layer located below the cerebral cortex that includes the forebrain, midbrain and hindbrain. 